\section{Mandatos militantes, vida cotidiana y subjetividad revolucionaria en el Movimiento de Izquierda Revolucionaria de Chile (1965-1975)}

Militant commands, daily life, and revolutionary subjectivity in the Revolutionary Left Movement in Chile (1965-1975)

\section{María Olga Ruiz**}

\section{Resumen}

El texto analiza rasgos de la subjetividad militante del Movimiento de Izquierda Revolucionaria en Chile (MIR 1965-1975). Desde un enfoque cultural que se apoya en las propuestas de Lechner y Williams, es posible comprender aspectos de la vida cotidiana de la militancia, y los motivos, razones y pasiones que movilizaron a quienes abrazaron el sueño de la revolución socialista. La pura adscripción racional a un proyecto político-ideológico explica sólo parcialmente la experiencia militante de hombres y mujeres que persistieron en sus propósitos políticos, aún en escenarios donde la derrota política era evidente.

Palabras clave: revolución, movimiento político, cultura política, socialismo.

\section{Abstract}

The following article analyzes some matters of militant subjectivity in the "Movimiento de Izquierda Revolucionaria" (Left Leaning Revolutionary Movement) (MIR 1965-1975). From a cultural point of view, supported by Lechner and Williams' theories, it is possible to understand some aspects of militants' every day life, their motivations, reasons, and the passions that mobilized those who embraced the dream of a socialist revolution. The mere rational adscription to a political-ideological project explains only partially the militancy of a man or a woman's experience that persisted on their political purpose, even when defeat scenario was imminent.

Key words: revolution, political movement, political culture, socialism. 


\section{Introducción}

Al igual que otras organizaciones revolucionarias conosureñas, el Movimiento de Izquierda Revolucionaria (en adelante MIR) construyó modelos identitarios entrelazando la vida cotidiana de sus militantes con definiciones político-ideológicas específicas. La militancia estaba cruzada no sólo por convicciones ideológicas y razones políticas, sino también por un entramado valórico y afectivo que, muchas veces, operó como el núcleo articulador de la identidad militante (Oberti 2011).

La propuesta de "Hombre Nuevo" guevarista llenaba de mística, pero también de exigencias a quienes abrazaban la promesa de la revolución socialista. Este proyecto consideraba no sólo la transformación radical de las estructuras políticas y económicas de las sociedades latinoamericanas, sino también la construcción de una nueva moral que liberara a los hombres (y mujeres) del estado de alienación al que se encontraban sometidos bajo el modelo capitalista. En este sentido, el socialismo no era un mero método de repartición, sino un sistema creador de nuevas conciencias y subjetividades, de modo que poseía una dimensión valórica indiscutible. El "Hombre Nuevo" debía constituirse al calor de las luchas revolucionarias, de modo que quienes se sumaban a la causa revolucionaria debían guiarse por un modelo claramente definido, y cuya máxima encarnación era la propia figura de Ernesto Guevara.

De acuerdo con estos planteamientos, el revolucionario era el escalón más alto de la especie humana, y por lo mismo, debía poner en práctica las virtudes y los valores asociados al modelo guevarista, a saber: la entrega total, el sacrificio permanente, la supeditación de los intereses personales y privados a los intereses colectivos, el coraje, la fuerza, la voluntad. Había que vivir y morir por la revolución, y el revolucionario debía actuar como un verdadero sacerdote de la causa revolucionaria. No obstante lo anterior, la práctica cotidiana de la militancia era diversa y, en esa pluralidad, incidían variados elementos: la edad, el género, la trayectoria política previa, la organización y el momento en que se militaba, entre otros.

En este artículo ${ }^{1}$ me propongo examinar aspectos de la vida cotidiana y la subjetividad militante del MIR, entre los años 1965, año de su fundación, y 1975, momento de la primera gran derrota político-militar de la organización (Palieraki 2014; Goicovic 2012; Leiva 2010; Pinto 2006, 2005; Sandoval 2004, 1990) ${ }^{2}$. De esta manera, pongo atención al siguiente problema: los procesos y mecanismos (formales e informales) a través de los cuales se construyen las identidades partidarias y la configuración de una cultura política militante con rasgos específicos.

Para lograr este objetivo he puesto el foco en la experiencia de los cuadros profesionales

El presente trabajo es parte un trabajo de investigación más amplio que se realiza en el marco del Proyecto FONDECYT Postdoctoral N³150169 titulado "Traicionar la revolución. La traición política en el PRT-ERP y Montoneros de la Argentina, el MIR de Chile y el MLN-T de Uruguay".

2 En 1975, y producto de la represión dictatorial, el MIR quedó prácticamente destruido en términos orgánicos. En 1976, Andrés Pascal retomó la conducción del Partido en el exterior, mientras que en Chile, Hernán Aguiló asumió como secretario interior de una organización que sólo contaba con cerca de 100 militantes. Al respecto, ver: Torres, O. 2010. La izquierda revolucionaria latinoamericana: Derrotas y readecuaciones. Los casos del Movimiento de Liberación Nacional-Tupamaros, MLN-T, de Uruguay y el Movimiento de Izquierda Revolucionaria de Chile. Tesis para obtener el Grado de Doctor en Estudios Latinoamericanos. Santiago: Universidad de Chile. 
del MIR, es decir, militantes que se dedicaban exclusivamente a las tareas designadas por la organización o que, manteniendo sus trabajos o estudios, subordinaban esas actividades a las tareas y urgencias de la actividad política. Para este fin he analizado bibliografía especializada acerca de la historia del MIR y otras organizaciones armadas conosureñas, documentos internos y prensa partidaria, tesis universitarias, testimonios escritos $y$ documentos personales de ex militantes ${ }^{3}$. Además, realicé entrevistas a personas que militaron en diversas estructuras partidarias en el período ya señalado 4 .

\section{El entramado cultural de la militancia política}

Como afirma el cientista político chileno-alemán Norbert Lechner (1986), la política, más allá de su dimensión instrumental y programática, posee una dimensión simbólica y subjetiva, de manera tal que la militancia nos remite a un mundo común, a un espacio en el que los sujetos reafirman su pertenencia a un colectivo que los antecede y trasciende. Estos planteos nos acercan a la noción de "cultura política", categoría que en la década de los 80 fue utilizada

\footnotetext{
Las fuentes primarias se desglosan a continuación:

- Archivos documentales: Centro de Estudios Miguel Enríquez (CEME-Chile), Centro de Documentación de los Movimientos Armados (CEDEMA).

- Prensa: El Mostrador, 5 de octubre de 2009
}

\footnotetext{
Un entrevistado solicitó ser citado con su nombre político, con el objeto de no exponer ni poner en riesgo su actividad profesiona actual. Las entrevistas se desglosan como sigue:

- Brito, Lucrecia. Santiago, agosto de 2010.

- Camilo (nombre político). Santiago, marzo de 2010.

- Díaz, Gladys. Santiago, septiembre de 2012.

- García, Enérico. Santiago, octubre de 2012.

- Muñoz, Gastón. Santiago, marzo de 2012.

- Ulloa, Luis. Santiago, diciembre de 2010.

- Videla, Lautaro. Santiago, noviembre de 2011.
}

por estudios que analizaban los procesos de transición a la democracia, poniendo atención a la dimensión cultural y a la subjetividad de los actores políticos que apoyaron o resistieron la emergencia de dictaduras cívico-militares. Asimismo, la emergencia de los movimientos sociales y la crisis de las "formas de hacer política" tradicionales, pusieron en el tapete los entramados culturales de la política, en especial aquella que se construía y desplegaba fuera de los espacios institucionales.

Esta noción ha sido utilizada para analizar una gran cantidad de problemas sociales, puesto que refiere a aspectos culturales, valorativos y subjetivos de los sujetos sociales que, en un sentido muy laxo, participaban de la vida política ${ }^{5}$. En relación con ello, Lechner rescata críticamente esta categoría, advirtiendo que su amplitud y extrema flexibilidad puede ser problemática. Señala el autor que "cultura política":
abarca de modo arbitrario, según las conveniencias del caso, una multiplicidad de aspectos dispares. El empleo demasiado extensivo y poco riguroso del término reduce su valor informativo. En realidad, la noción carece de fundamentación teórica y ello dificulta el análisis empírico; por consiguiente, resulta complicado especificar su contenido concreto (...). No obstante estas objeciones, no debiéramos renunciar, por purismo científico, al empleo del término. Su uso en el lenguaje cotidiano y en el debate intelectual indica su utilidad para señalar un campo que si no quedaría en la oscuridad. Es cierto que carecemos de un concepto de cultura política; pero el fenómeno existe (Lechner 1987: 10).

\footnotetext{
Una de las definiciones más aceptadas de esta noción es la propuesta por los trabajos de Almond y Powell, quienes la entienden como: "cultura cívica, la que considera las actitudes individuales respecto a la política, incluyendo las orientaciones cognitivas, las creencias, orientaciones afectivas, sentimientos de apego, compromisos y rechazos respecto de los objetos políticos, entre otros elementos" (1966: 48).
} 
De esta forma, esta noción refiere no tanto a las acciones políticas como a las orientaciones que las guían, es decir, a los estilos y los modos de hacer y concebir la política. Ello supone poner atención a la producción subjetiva de los sujetos y a los marcos valóricos y emocionales que sostienen la acción política.

Así, las identidades políticas se articulan en torno a acciones programáticas y también a elementos simbólicos, como mitos y ritos que refuerzan el sentido de lo colectivo y la concepción del mundo ligada a esta pertenencia. Mientras que los ritos son una instancia colectiva en la que se recrea, actualiza y consolida la identidad colectiva, los mitos permiten organizar una interpretación del mundo que da sentido a la acción política, situando a la comunidad en una temporalidad específica que le permite reconocerse como parte de una trayectoria histórica de largo alcance.

En relación con este último punto, es preciso señalar que la comprensión del mito como motor de la acción colectiva fue advertida tempranamente por el intelectual peruano José Carlos Mariátegui, fundador de la revista Amauta en 1926, y autor de "Siete ensayos de interpretación de la realidad peruana". Este autor, en la década del 20 del siglo XX, afirmó que los mitos revolucionarios podían activar la voluntad colectiva de los pueblos, asignándole a sus luchas una fuerza y un poder histórico innegable. Señala Mariátegui:

No se vive fecundamente sin una concepción metafísica de la vida. El mito mueve al hombre en la historia. Sin un mito la existencia del hombre no tiene ningún sentido histórico. La historia la hacen los hombres poseídos e iluminados por una creencia superior, por una esperanza superhumana; los demás hombres son el coro anónimo del drama (...). Lo que más claramente diferencia en esta época a la burguesía y al proletariado es el mito. La burguesía no tiene ya mito alguno. Se ha vuelto incrédula, escéptica, nihilista. El mito liberal renacentista ha envejecido demasiado. El proletariado tiene un mito: la revolución social. Hacia ese mito se mueve con una fe vehemente y activa. La burguesía niega; el proletariado afirma (1988: 281).

Estas reflexiones fueron elaboradas en un contexto particular: la realidad peruana y el deseo de Mariátegui de construir el socialismo en un país que no poseía un proletariado fuerte ni un desarrollo industrial significativo. Como fundador del Partido Socialista peruano, mantuvo independencia de los lineamientos de la Tercera Internacional y, en lugar de sumarse a la política de bolchevización y a la conformación de un partido proletario clásico, propuso una concepción original sobre el marxismo, la que asignaba un lugar central a la cuestión moral y espiritual, pues, apelando a sus propias palabras, "cada palabra, cada acto del marxismo tiene un acento de fe, de voluntad, de convicción heroica y creadora" (Mariátegui 1934: 58).

Apoyándose en la teoría soreliana de los mitos revolucionarios (Sorel 2005) ${ }^{6}$, Mariátegui propone que ni la ciencia ni la razón logran satisfacer las inquietudes y necesidades humanas, y que, por lo tanto, la voluntad, la pasión y la fe son los elementos indispensables para movilizar a los sujetos tras la promesa de la revolución socialista. El mito revolucionario se sostiene, entonces, en una fuerza religiosa, mística y espiritual.

El filósofo francés Georges Sorel es reconocido como teórico del sindicalismo revolucionario, y como autor de Reflexiones sobre la violencia, texto en el que aborda el potencial revolucionario del mito y defiende el uso de la violencia como forma de enfrentar y derrotar la fuerza del estado burgués. 
Retomando esos planteamientos, en este trabajo asumo que la experiencia militante no se explica únicamente en la mera adscripción a una ideología en particular, sino que constituye una forma de leer y de vivir la realidad. Es, en este sentido, una cultura, tal como la entiende Raymond Williams (2009) y otros teóricos de los Estudios Culturales.

Desde una cercanía crítica respecto del marxismo, Williams (2009) propuso la noción de "materialismo cultural", la que expresael espesor material de la cultura y su lugar en la formación de prácticas y relaciones sociales, instituciones y producciones simbólicas. El autor entiende la cultura en un sentido antropológico, es decir, como modo global de vida sin restringirla a las actividades ni los objetos asociados al trabajo intelectual o artístico. Asimismo, asume que la realidad social y material está estructurada en base a valores, imágenes y significaciones, estableciendo un vínculo estrecho entre cultura y lenguaje.

A partir de esta mirada, se entiende que la realidad se construye a través de una red de relaciones donde lo político, lo social, lo económico y lo cultural interactúan entre sí, de modo que la explicación de los fenómenos sociales no depende sólo de uno de esos aspectos. Es así como las estructuras (entendidas como la dimensión social y económica) y las superestructuras (entendidas como la esfera política e ideológica) están interrelacionadas, pues ambas refieren a actividades humanas concretas que son productivas en tanto participan activamente en la construcción de la realidad. De allí que cualquier intento por establecer una división tajante constituya una abstracción que obtura la posibilidad de comprender la sociedad.
En esta misma línea, la categoría de "estructura de sentimiento" permite analizar cómo esos valores fueron vividos y sentidos por los sujetos, así como la forma en que esos sentimientos se articularon con ideas que habían sido formuladas formal y sistemáticamente. Esta noción hace posible advertir la manera en que el pensamiento es sentido y, a su vez, los sentimientos son pensados, superando la disyunción entre una y otra dimensión de la experiencia humana. Asimismo, permite comprender el modo en que ciertas ideas son incorporadas por los sujetos a su cotidianeidad y, a partir de ahí, son pensadas y sentidas de un modo particular en el que se articulan lo social y lo individual. Indica Williams:

El término resulta difícil; sin embargo, "sentimiento" ha sido elegido con la finalidad de acentuar una distinción respecto de conceptos más formales como "concepción del mundo" o "ideología". No se trata solamente de que debamos ir más allá de las creencias sistemáticas y formalmente sostenidas, aunque por supuesto siempre debamos incluirlas. Se trata de que estamos interesados en los significados y valores tal como son vividos y sentidos activamente (2009: 180).

Esta propuesta es muy productiva para comprender la vida cotidiana $^{7}$ de la militancia y los motivos, razones y pasiones que movilizaron a quienes abrazaron el sueño de la revolución socialista. La pura adscripción

Entiendo la vida cotidiana en los términos en que la define Norbert Lechner: "En lugar de reducir los procesos microsociales al plano del individuo (en contraposición a la sociedad) habría que visualizar la vida cotidiana como una cristalización de las contradicciones sociales que nos permiten explorar la textura celular de la sociedad de algunos elementos constitutivos de los procesos macrosociales y desde allí cuestionar, problematizar y reconfigurar el análisis de lo social desde este campo de análisis de los contextos en los cuales diferentes experiencias particulares llegan a reconocerse en identidades colectivas (...). Vista así, la vida cotidiana se ofrece como un lugar privilegiado para estudiar, según una feliz expresión de Sartre, lo que el hombre hace con lo que han hecho de él" (1987: 65-66). 
racional a un proyecto político-ideológico explica sólo parcialmente la experiencia militante de hombres y mujeres que persistieron en sus propósitos políticos, aun en escenarios donde la derrota política era evidente. La comprensión de esa porfía sólo puede ser entendida poniendo atención al entramado valórico, ideológico y emocional que configuró la subjetividad revolucionaria de los 60 y 70 .

Asumiendo que la cultura opera como un sistema de significación a través del cual se vivencia y construye la experiencia social, es posible poner el foco en los sentidos asignados a las prácticas sociales (y a quienes tienen el poder para definir esos significados), entendiendo la centralidad que adquieren la subjetividad y las configuraciones identitarias en la puesta en marcha de proyectos emancipatorios. Estas definiciones permiten comprender las prácticas culturales cotidianas como el escenario donde se despliega y construye un determinado tipo de prácticas políticas, visibilizando así dimensiones menos evidentes de la experiencia militante.

En una dirección similar, el intelectual chileno Bernardo Subercaseaux propone la noción de "imaginario político" para referirse a:

\begin{abstract}
un conjunto articulado de representaciones con un núcleo ideológico y un campo léxico y semántico común, que involucra también una dimensión cultural $e$ incluso emocional. En cuanto representaciones, éstas portan un contenido ideológico, un marco conceptual, un determinado lenguaje y una retórica, referentes simbólicos y pulsiones culturales (2004: 52).
\end{abstract}

En este sentido, la militancia en organizaciones políticas supone la confluencia entre ideas y pulsiones culturales, articulándose estilos de vida singulares y distintivos, que consideran desde un cierto tipo de vestimenta hasta usos lingüísticos específicos. Tanto así, que la identidad cultural partidaria sobrepasa los elementos estrictamente ideológicos, y puede persistir en el tiempo, incluso si la estructura orgánica partidaria se divide o desaparece. Así, la organización política existe en tanto comunidad humana en la que se cruzan los afectos y las ideas, las razones y las pasiones, lo privado y lo público, y en la que las acciones políticas son vividas, sentidas y pensadas de un modo particular.

Los testimonios de ex militantes y diversas investigaciones académicas advierten que el proyecto revolucionario de los 60 y 70 descansaba sobre una visión de mundo y una concepción de la revolución como un absoluto que asignaba un sentido y un lugar en la historia a sus miembros. La militancia imponía a los militantes -en especial a los profesionales o de tiempo completo- mandatos y estrictos patrones de conducta. Asimismo, el ingreso al MIR consideraba distintas etapas (simpatizante, aspirante, militante), cada una de las cuales suponía el cumplimiento de ciertas exigencias, y en muchos casos, una evaluación más o menos formal de parte de un encargado. Se trataba, en suma, de un proceso regulado y controlado que consideraba ritos que reforzaban el tránsito de afuera hacia adentro (Naranjo et al. 2004).

La moral revolucionaria consideraba modos de comportamiento claramente establecidos, y esos mandatos, escritos o no, se mantuvieron, y en muchos casos, se rigidizaron en el escenario posterior al golpe cívico-militar de 1973. La implementación del proyecto político revolucionario requería la formación moral y política de sujetos que debían poseer características particulares: decisión, valor, coraje, fortaleza, convicción y arrojo. 
Así también, se asumía que la voluntad era suficiente para poner en marcha el proceso revolucionario y despertar las conciencias de los oprimidos. Tal como señala Alain Badiou (2005), a fines del siglo XIX y comienzos del siglo XX, ocurrió un desplazamiento desde el progresismo histórico al heroísmo político histórico, tránsito que se explica en el convencimiento de que la historia sólo puede avanzar forzándola a ello. La voluntad aparece, entonces, como el motor de la historia, ocupando un lugar central en la subjetividad revolucionaria.

Siguiendo esta perspectiva analítica, los trabajos de Julián Bastías (1995), Tamara Vidaurrázaga (2006) y Hernán Vidal (1999) se acercan a la subjetividad militante y a la cultura política de la organización que analizamos, poniendo atención a las tensiones y los nudos problemáticos que acompañaron la experiencia de la militancia revolucionaria setentista. La maternidad, las relaciones de género, la disciplina interna, los mandatos que organizaban y estructuraban la vida diaria, son algunos de los tópicos abordados por estos autores.

\section{Llamados por la "Historia"}

Muchos de los jóvenes que se sumaron al MIR lo hicieron movilizados por un ánimo contestatario y crítico que se nutría no tanto de concepciones político-ideológicas, sino de un profundo rechazo al sistema imperante. Ese descontento se manifestaba en un cuestionamiento general a todo lo establecido: desde la guerra de Vietnam hasta el mandato de la virginidad; todo debía ser reinventado.

Al impacto provocado por el triunfo de la Revolución Cubana y por las luchas anticolonialistas en Asia y África, se sumaban transformaciones culturales que modificaban la vida cotidiana de hombres y mujeres, como el uso de anticonceptivos y el cuestionamiento a la moral sexual conservadora. Todo gesto de autoritarismo era cuestionado: desde la política imperialista de los EE.UU., hasta la autoridad paterna al interior del núcleo familiar. De este modo, en los largos sesenta (Devés 2003) fueron desestabilizándose los ordenamientos de la vida pública y privada, articulando en un mismo reclamo la lucha por el socialismo, el ejercicio de una sexualidad sin ataduras y la liberación de los oprimidos. Existía el convencimiento de que el sistema, noción bastante amplia e imprecisa que aludía a todo lo establecido, era esencialmente injusto $\mathrm{y}$, por ello, era preciso transformarlo.

Es así como, independientemente de cómo se llegara a la militancia política, la incorporación a esta organización implicó un nuevo modo de relacionarse con los otros y consigo mismo, una ruptura drástica (y muchas veces definitiva) con la vida anterior. El llamado de la historia resultó ser poderoso y casi siempre ineludible, pues se nutría tanto de promesas como de certezas.

Tal como señala la ex militante del MIR, Gladys Díaz, en relación con sus primeros acercamientos a la militancia política:

Yo me crie en una situación en la que no podía si no ser militante de izquierda, en un pueblo minero, con gente muy pobre, leñeros, carboneros, y estaban los chilenos y los norteamericanos. Yo era hija de uno de los hombres de mejor situación (mi papá era comerciante) y desde muy niña vi cosas muy brutales... Me tocó presenciar cosas que yo tendría que haber sido una persona muy insensible o psicópata para no haber sentido desde muy niña lo que era la desigualdad en este país (...) ésa fue mi primera motivación para meterme a lo social. 
Los revolucionarios tenían la obligación de realizar cambios en la totalidad del individuo, poniendo sus acciones, afectos e inteligencia al servicio de la colectividad. El cumplimiento de esos deberes iba acompañado de sentimientos de satisfacción, constituyéndose en un sacrificio gozoso para la mayoría de los militantes.

Un rasgo distintivo de esta identidad es la renuncia, en primer término, a sí mismo, es decir, una suerte de abandono del propio yo en el marco de un proceso de fusión con el colectivo. Un cuadro político revolucionario debía estar dispuesto a renunciar a la familia, a los estudios, al desarrollo profesional y a la propia vida si la revolución así lo exigía. En este sentido, resulta paradójico que la afirmación de la identidad revolucionaria consistiera, justamente, en lo que el ex militante Julián Bastías ha definido como proceso de "desindividualización", formulado como "entrega a la causa" (2005: 176).

La máquina revolucionaria exigía una entrega total y los militantes eran una pequeña pieza de un engranaje mayor al que se debían por entero. En este sentido, el compromiso con la revolución se sostenía en una especie de "borramiento de sí mismo en el colectivo" (Oberti 2011: 190), de modo que los proyectos personales quedaban desplazados por un proyecto de transformación global del que se beneficiarían todos los excluidos y oprimidos del mundo.

\section{De acuerdo a Camilo, ex militante del MIR:}

En verdad, toda mi vida fue al servicio del MIR, en todo ese tiempo. Yo creo que el concepto era que la comunidad era más importante que el individuo, entonces, por ejemplo, yo quería ser médico, pero un médico revolucionario, no quería ser un médico cualquiera. Pero para ser un médico revolucionario, ¿qué es lo que había que tener primero? había que tener revolución. Entonces si tú no hacías la revolución, no ibas a ser un médico revolucionario, y si tú querías ser un revolucionario tenías que hacer la revolución. Por lo tanto, tus intereses personales estaban supeditados a los intereses de la comunidad y la comunidad era el Partido, la comunidad era la revolución y la comunidad era la sociedad. Entonces, desde esa perspectiva, no era ningún dolor trasladarse de ciudad, trasladarse de tarea o dejar los estudios o dejar el trabajo que tenía. Eso no es importante desde esa perspectiva. La perspectiva y el marco general era la revolución ${ }^{8}$.

La máxima expresión de la renuncia total era la disposición a morir, posibilidad que era parte del escenario de probabilidades tratándose de una organización que apostaba a la lucha armada como estrategia para instalar el socialismo en Chile. Como es lógico, una vez ocurrido el Golpe de septiembre de 1973, la proximidad de la muerte se hizo más concreta y cercana. Señala Lautaro Videla, ex mirista:

Yo partí pensando que el acto más sublime de la política es terminar muriendo por los ideales. Nosotros nos formamos en esa lógica, o sea, para nosotros era obvio que nuestra salud estaba en riesgo, nuestra familia estaba en riesgo ¿me entiendes? Había que asumirse como parte de un engranaje, una rolinera de estas bolitas de metal de acero, que a veces se rompen y que si se rompen hay que cambiarlas. Por lo tanto, éramos una rolinera del engranaje del proceso de la revolución y si nos tocaba, nos tocaba. Pero con ese agregado de que si nos toca, va a ser un ejemplo, la parte sublime de nuestro rol político.

La muerte en combate sellaba una vida entregada a los otros. Así lo señalaba la experiencia de Guevara y de otros dirigentes revolucionarios, como Miguel Enríquez o Roberto Santucho. La dimensión sacrificial de la militancia, dar la vida por la vida, otorgaba

\footnotetext{
La cursiva es mía.
} 
la posibilidad de trascender y de servir como ejemplo a los futuros revolucionarios. De esta manera, no se trataba de una muerte cualquiera, sino de una muerte luminosa, trascendente y sublime. En palabras de Camilo:

Creo que a la edad que tenía yo, a los 20 años, la muerte es un hecho casi lindo si se producía en esas circunstancias (el combate). Nosotros teníamos muy poca experiencia acerca de la muerte, como no fuese la de nuestros abuelitos en una cama enfermos con cáncer o algo así. Pero la muerte desde la perspectiva revolucionaria era una cosa frente a la que no teníamos dolor ni miedo. Al contrario, era una cosa casi gloriosa. Desde esa perspectiva no era algo que nos amilanara. En absoluto.

El ánimo contestatario y rebelde de quienes aspiraban a ser militantes de las organizaciones revolucionarias debía ser encuadrado para que fuera funcional al proyecto político que se perseguía. Los jóvenes rebeldes debían transformarse en militantes disciplinados, responsables y aplicados y, para ello, las tres organizaciones aquí analizadas pusieron en práctica diversos mecanismos de formación política (Naranjo 2004) ${ }^{9}$, por ejemplo, escuelas de formación de cuadros, la lectura conjunta de la prensa partidaria, instrucción militar, entre otras. Con respecto a este punto, el ex militante del MIR, Julián Bastías, se pregunta desde una mirada retrospectiva bastante crítica "¿cómo entender que estos individuos atraídos por el espíritu de rebeldía, creativo y libertario que el MIR representaba, se adaptaran rápidamente a valores tan diferentes?" (2005: 170).

En el caso del MIR, la necesidad de transformar a sus militantes en cuadros políticos

Estos mecanismos no son, por cierto, exclusivos de la izquierda revolucionaria, sino que una práctica extendida en las organizaciones políticas de izquierda en general. profesionales requirió la puesta en marcha de estrategias de educación política cada vez más estructuradas. Este proceso se inició en 1969 (dos años después de que Miguel Enríquez asumiera su conducción), y fue parte de una restructuración orgánica más amplia, orientada a fortalecer políticamente al Partido. Entre las medidas adoptadas se consideró el establecimiento de etapas para regular y controlar el ingreso y la formación de los militantes. Para la nueva conducción, el fortalecimiento del Partido hacía indispensable la formación de un nuevo tipo de militante. Tal como señala un documento partidario: "[l]os aficionados deberán abandonar la organización. (...) No se ingresará ni se hará abandono del Partido de cualquier forma. La entrega de sí mismo deberá ser total. La organización decidirá si un militante debe o no trabajar o estudiar, o dónde habitar, etc." (Naranjo 2004: 62).

Durante este período -previo al golpe cívicomilitar de 1973-, y con el objeto de regular y controlar el ingreso a la organización, se establecieron las etapas de simpatizante, aspirante y militante. De acuerdo a lo propuesto, el período de formación debía extenderse por, al menos, seis meses, proceso en el cual se ponía a prueba la capacidad de entrega y disciplina de los futuros militantes.

El proceso formativo consideraba el conocimiento y la comprensión de las siguientes materias: aspectos generales de la teoría marxista-leninista (materialismo dialéctico, materialismo histórico, economía política), historia del movimiento obrero mundial y nacional, historia del Partido y estructura de la formación social chilena. Asimismo, se esperaba que los militantes tuvieran un manejo general de aspectos orgánicos, técnicos y 
militares, con el objeto de poder aplicar en su quehacer cotidiano los aspectos más teóricos e ideológicos. Un buen militante debía estudiar y conocer las obras clásicas del pensamiento marxista-leninista, así como los escritos de líderes revolucionarios contemporáneos cuya experiencia era considerada como un ejemplo a seguir: Guevara, Giap, Fanon, entre otros.

Además, un aspecto central en la formación militante tenía relación con cuestiones morales y valóricas. Como señala un documento partidario que abordaba el tema de la formación de los cuadros políticos:

El Partido Revolucionario debe transformar a sus militantes, convertirlos en acero bien templado, sensible y flexible, pero no quebradizo, capaz de hacer frente tanto a las incitaciones de la sociedad burguesa a una vida cómoda, al individualismo, al provecho personal, como de hacer frente a la represión, a la persecución, a la tortura, capaz de continuar la lucha con más fe en el triunfo del proletariado que nunca (MIR 1974: 1).

De acuerdo a estos modelos y representaciones, los valores revolucionarios estaban asociados a la fortaleza, la entereza, el estoicismo, los que, a su vez, se definen por oposición a lo quebradizo, lo frágil, lo débil. Asimismo, esa fortaleza debía utilizarse para resistir no sólo al enemigo externo, sino a conductas internas que era preciso erradicar y eliminar: el individualismo, las comodidades de la vida burguesa, el provecho personal.

Esa transformación interna debía hacerse, necesariamente, dentro del Partido y al calor del fuego y los golpes de la lucha de clases. De este modo, si bien el manejo -aunque fuese general- de cuestiones teóricas era indispensable, y con ese fin se elaboraron manuales que resumían las obras de Engels,
Marx y Lenin, la práctica revolucionaria era, en definitiva, lo más importante. Tal como advierte Lautaro Videla, ex dirigente que tuvo a su cargo la formación política de otros militantes:

\begin{abstract}
A los simpatizantes y aspirantes tratábamos de vincularlos al conocimiento del pensamiento político marxista, pero lo más importante era la actividad concreta, de compromiso, es decir, desarrollar algunas acciones que demostraran su disposición a jugar un papel en la lucha, que fuera capaz de hablar o que fuera organizador. Valorábamos mucho al que organizaba, al que trabajaba en la oscuridad, oscuro, triste y gris, armando reuniones, consiguiendo recursos, que entregara tiempo y dedicación a la actividad política del $\mathrm{MIR}^{10}$.
\end{abstract}

La evaluación sobre el desempeño de simpatizantes y aspirantes, y la posibilidad de ascenderlos (o no) a la condición de militantes, estaba en manos de los dirigentes de cada estructura, cuya decisión debía ser confirmada posteriormente por las estructuras superiores del Partido. Ahora bien, la experiencia del tránsito del afuera hacia adentro fue diversa. Como señala Videla, el proceso de formación variaba dependiendo del tipo de militante: mientras a los estudiantes universitarios se les exigía un mayor manejo de aspectos teóricos e ideológicos, los que provenían del mundo sindical y campesino debían demostrar otro tipo de destrezas, más vinculadas al activismo y a capacidades organizativas. Como advierte el mismo dirigente:

En el mundo campesino y sindical lo más determinante era el activismo, ir a una reunión, convocar a sus colegas a que votaran por una determinada posición en el sindicato. En la población, en los sin casa, lo mismo, los campesinos igual. Eso era más determinante que la formación ideológica y los grados de información política. Esto porque había intereses de clase, había una sensibilidad que tenía que ver con su

10 La cursiva es mía 
vida cotidiana que lo hacía comprometerse mucho más fácil que un cabro que necesitaba una serie de argumentos ideológicos, para llegar a entender casi abstractamente que era bueno luchar por la reforma agraria y el huevón [sic] no tenía más que un jardín en su casa. Ese tenía que abstraer más y acceder a niveles de conocimiento, cultura y de teoría mayores. Había no una discriminación, una diferenciación en las exigencias ${ }^{11}$.

De acuerdo a este testimonio, se consideraba que los militantes de extracción pequeño burguesa debían corregir las carencias y deformaciones asociadas a su origen a través del estudio y el conocimiento de la teoría marxista. Se entendía, en un mismo sentido, que quienes provenían de sectores populares tenían, por su experiencia directa y cotidiana con la explotación, más facilidad para acceder a la conciencia revolucionaria y, por lo mismo, su desarrollo político-intelectual no era prioritario (Bastías 2005).

Mientras algunas personas recuerdan el momento preciso en que se les comunicó oficial y formalmente que fueron aceptadas como militantes de la organización, otras afirman haber ingresado sin ningún tipo de restricciones. Es necesario señalar que, en algunos momentos, las medidas de selección y formación no fueron implementadas ya que las urgencias del contexto político no lo hicieron posible. De hecho, muchos de quienes ingresaron a la organización durante el período de la Unidad Popular, y en especial a partir del año 1972 (período de mayor crecimiento orgánico), fueron aceptados de inmediato, sin recibir ningún tipo de formación especial, dada la enorme cantidad de actividades y tareas partidarias que había que realizar.

\footnotetext{
11 La cursiva es mía.
}

Después del golpe cívico-militar de 1973, el ingreso masivo y automático de militantes fue considerado por la Dirección como una grave debilidad que explicaba, al menos en parte, los numerosos embates recibidos por parte de los aparatos represivos. Los militantes nuevos, inexpertos y sin formación política, eran -desde esa perspectiva- más propensos a cometer errores de seguridad y a no respetar la compartimentación, lo que hacía más vulnerable al Partido (MIR 1974). Lo cierto es que la implementación de estos procesos educativos no fue una experiencia uniforme, al contrario, muchas veces fue irregular y poco sistemática, siendo desplazada por otras tareas consideradas más urgentes ${ }^{12}$.

Adicionalmente, la noción leninista de vanguardia política y la moral revolucionaria guevarista fueron elementos centrales en la construcción de la identidad mirista. De acuerdo a estos preceptos, se entendía que el Partido estaba formado por los mejores hijos del pueblo, quienes tenían la misión de conducir y formar a las masas en los valores de la moral revolucionaria y, para ello, debían demostrar con el ejemplo que reunían todas (o al menos gran parte de) las virtudes del "Hombre Nuevo". Los miristas eran y debían ser los mejores. Señala Videla:

Mira, nosotros éramos como los griegos de la izquierda, la crème de la crème de la izquierda chilena. Miguel era un tipo brillante; el Guti era muy ilustrado, cultísimo; Sotomayor un corajudo, aguerrido; Edgardo era genial, lo mismo el Bauchi...

Como Partido de cuadros, el MIR requería militantes de tiempo completo, sin embargo, la formación de los Frentes Intermedios hizo posible que muchos jóvenes se incorporaran a la organización sin necesidad de abandonar sus estudios o trabajos. Estos frentes, cuyo objetivo era desarrollar un trabajo político con los sectores estudiantil, obrero y campesino, sirvieron de cantera para captar a nuevos cuadros. 
un equipo excepcional. Es cierto que se nos acusó hasta de ser agentes de la $\mathrm{CIA}$, pero creo que mucha gente nos admiraba por nuestro arrojo, nuestro compromiso y nivel de entrega.

La idea de excepcionalidad señalada por el ex militante expresa una concepción de sí mismos que contiene, al menos, dos sentidos. Por un lado, considerarse únicos, particulares, diferentes $y$, por otro lado, mejores, superiores y aventajados en relación con los militantes de otras organizaciones políticas y, por cierto, respecto de los sujetos comunes y corrientes que no habían despertado a la conciencia revolucionaria.

Es preciso considerar que tanto en el MIR como en otros partidos de izquierda conosureños -incluidos los de izquierda tradicional-, los dirigentes (muchas veces fundadores de la organización) eran considerados la encarnación del militante ideal. A ellos -la mayoría bastante jóvenes-, se les respetaba y admiraba por su inteligencia, oratoria magnífica, coraje y entrega total a la causa revolucionaria. El hecho de que algunos de los dirigentes proviniesen de familias acomodadas, era observado como una prueba irrefutable de su capacidad de renuncia y compromiso con los oprimidos. Se les consideraba personas excepcionales e intelectualmente brillantes. A su vez, su participación en las acciones armadas ponía en evidencia que estaban dispuestos a asumir los riesgos que el proyecto exigía. De este modo, el ejemplo de los dirigentes modelaba la identidad de los militantes, tanto o más que los cursos y manuales de formación política. Como señala Patricio Rivas, ex dirigente del MIR:

su juventud se transformaba en un imán para quienes teníamos menos de veinte años. En todos existía una postura de valentía que comunicaban con la mímica de sus cuerpos. "No le tememos a la historia", parecían decir con sus gestos. Sugerían una estética, una ética y una política. Se vestían con parkas, chaquetones azules, jeans, pantalones de cotelé oscuros y bototos. Hablaban sin afectación pero con identidad. Cientos de muchachos nos sentiríamos atraídos por esa energía (2007: 20).

En efecto, los dirigentes ejercían un liderazgo que descansaba tanto en elementos racionales como emocionales, actuando como intermediarios entre el proyecto y el conjunto de los militantes. Se buscaba imitar sus virtudes, gestos y hasta su forma de vestir, y condensaban en sí mismos los atributos que la comunidad considera deseables.

Para los militantes que se incorporaron a la organización después del golpe de septiembre de 1973, la historia de sus dirigentes, en especial la de aquellos que murieron asesinados por los aparatos represivos y que en los primeros años de vida de la organización participaron en acciones armadas (fundamentalmente, asaltos a entidades bancarias), operaba como un mito que fortalecía la adhesión colectiva y la identidad militante.

En cuanto a su estructura organizativa, entre 1970 y 1973 la organización interna del MIR estuvo estructurada de la siguiente manera: la militancia de base se organizaba en torno a los Grupos Político Militares (GPM), órganos de carácter territorial que estaban vinculados con los frentes de masas. Por encima de estas estructuras estaban los Comités Regionales (CR), y más arriba se hallaba el Comité Central (CC), órgano de dirección formado por los dirigentes de los Comités Regionales, por los miembros que habían sido elegidos en el III Congreso (realizado en 1967), y por los militantes de confianza que habían sido cooptados. En la cima de la pirámide estaba la Comisión 
Política (CP), y en su interior se encontraba el Secretariado Nacional, quien asumía la dirección y la representación del Partido.

Esta estructura jerárquica, propia de un partido leninista, se vio reforzada con la postergación del IV Congreso y con el uso reiterado de la cooptación como mecanismo de ascenso en las estructuras partidarias. Este tipo de organización interna asignaba a los máximos dirigentes un poder difícil de contrarrestar, situación que en el periodo analizado no fue mayormente cuestionada -al menos de forma articulada y masiva- por la militancia. Como recuerda el ex militante Luis Ulloa:

\begin{abstract}
Mira, yo no participé nunca en una elección, no existía eso, además era una estructura políticomilitar entonces nos sometíamos al mando, yo tenía un jefe, él venía con los acuerdos que se habían tomado en otra instancia en la cual yo no tenía ninguna participación... Pero no fue posible, el contexto no permitió hacerlo de otra forma, además que todos respaldábamos a nuestra Dirección, nadie los cuestionaba, para nada... no discutíamos, pero a nadie le importaba, no era un tema, teníamos claro el camino... en lo central estaba todo claro, nosotros teníamos una lucha donde no se daban esas cosas, el tareísmo mataba lo otro, ahogaba la discusión de otros temas, nosotros peleábamos pero con el PC, no adentro... Nunca escuché que alguien reclamara, por primera vez lo escuché preso, en Puchuncavi, nunca antes... nosotros teníamos una cuestión de fe hacia nuestros líderes, o sea Miguel era médico, Bauchi médico, el Dago sociólogo, o sea (...) ellos podían acceder a una vida cómoda dentro del sistema, pero ellos optaron por otra cosa y era seductor eso, entonces yo no andaba pensado si habrán usurpado el poder, que por qué no habrán elecciones... no era mi problema.
\end{abstract}

En relación con este punto, algunos dirigentes de la época señalan que, si bien existía un excesivo verticalismo, esto no provocaba mayores conflictos ya que había una suerte de coincidencia armónica entre las aspiraciones e inquietudes de las bases militantes y las decisiones políticas de la Dirección (Leiva 2010). Existen, sin embargo, diversos registros que dan cuenta de que aún antes del golpe militar, existían algunos sectores de la militancia que no aceptaban de buena gana la escasa democracia interna y que plantearon sus diferencias. Años más tarde, documentos oficiales del Partido harían suyos esos mismos cuestionamientos (Calderón 2009).

\section{Amor, vida cotidiana y revolución}

En muchos sentidos, la intensidad de la vida militante hizo que la organización política se constituyera en una nueva familia para sus militantes, transformando los lazos políticos en poderosos vínculos afectivos. La familia de origen fue abandonada o desplazada por las tareas partidarias, y tanto la fuerza de las convicciones como la certeza de que se podía morir por la causa revolucionaria reforzaban la identidad colectiva de los militantes. Como señala el ex dirigente del MIR, Lautaro Videla:

\begin{abstract}
Había una relación casi amorosa, entre hombres, entre mujeres, un sentimiento de amor, de afecto. Estábamos en la misma pelea, abandonando todo, arriesgándolo todo, teníamos que tener un espacio familiar, chucha [sic] teníamos que tener algo que nos diera un sentido de pertenencia. Un sentido de protección. Sí, éramos una verdadera familia, no me cabe duda de eso.
\end{abstract}

De este modo, la pertenencia a una organización fue una fuente de gratificaciones afectivas. Este aspecto es decisivo para comprender la identificación política con la comunidad y las dificultades y costos que suponía abandonarla (en especial cuando la salida no era voluntaria). 
La transformación de los militantes debía ser integral, involucrando tanto su vida pública como privada. No se trataba de un proyecto y una cultura política que considerara transformaciones radicales única y exclusivamente en la esfera de la política formal y la economía, sino, más bien, de una colonización de lo privado y personal por parte de lo público, en este caso, la revolución socialista. Así se señala en el documento "Notas sobre la formación de los cuadros", atribuido al dirigente Martín Hernández, quien estaba a cargo de la Comisión Nacional de Formación Política.

No es una parte -la parte pública- del militante la que está dentro del Partido mientras que la otra -la parte privada- queda fuera y sometida a otras leyes, normas y valores morales; el militante revolucionario debe ser tal, tanto en su actividad política como en su actividad privada y en ambas debe constituirse en ejemplo de una nueva moral y del inicio del proceso de constitución del futuro hombre total del socialismo (MIR 1974: 17).

Si bien es posible advertir una coincidencia entre esta afirmación y la politización de lo privado propuesta por el feminismo en la misma época (Oberti 2011), lo cierto es que el proyecto revolucionario no consideraba una revalorización de las relaciones personales ni de la vida cotidiana. Por el contrario, la esfera de lo íntimo debía subordinarse a las exigencias de la gran política. De esta manera, la construcción de los vínculos afectivos primarios estaba condicionada por el ritmo y por los mandatos de la revolución, tal y como lo había señalado el propio Guevara en el clásico escrito "El Socialismo y el hombre en Cuba" de 1965:

Los dirigentes de la Revolución tienen hijos que en sus primeros balbuceos, no aprenden a nombrar al padre; mujeres que deben ser parte del sacrificio general de su vida para llevar la Revolución a su destino; el marco de los amigos responde estrictamente al marco de los compañeros de Revolución. No hay vida fuera de ella (Guevara Cit. en Fernández 1999: 127).

Sin embargo, la articulación entre el mundo de la afectividad y el mundo de la política sí estuvo cruzada por tensiones y conflictos que llevaban la marca del género. El proceso de transformación en un "Hombre Nuevo", no era, como es evidente, igual para mujeres y hombres. La militancia en organizaciones político-militares les permitió actuar en el espacio público, asumir diversos liderazgos y participar en la construcción del proyecto revolucionario. Paradójicamente, al mismo tiempo que se constituyó en un espacio de desarrollo personal y político (Vidaurrázaga 2006), ese espacio no cuestionó la condición de desigualdad de las mujeres ni otorgó valor a las cuestiones vinculadas con la vida privada.

En un escenario mundial marcado por la subversión de las pautas sociales en el plano moral, sexual y familiar, la experiencia militante estuvo atravesada por la coexistencia-no pocas veces conflictiva- entre prácticas contestatarias y una moral más rígida y conservadora. La mayoría de los entrevistados recuerda que las relaciones personales se desarrollaban con bastante libertad $y$, de hecho, el MIR no formuló un código de conducta que regulara las relaciones entre sus miembros. No obstante, en algunas ocasiones hubo una suerte de control "entre pares", es decir, de militantes que cuestionaron las conductas de otros militantes, por no ajustarse a los códigos de la conducta revolucionaria. Como recuerda Gastón Muñoz, ex militante de esta organización:

Yo fui presidente de la Federación de Estudiantes, miembro del consejo superior de la Universidad 
de Concepción por el MIR, entonces una vez fui cuestionado por un compañero peruano porque eh... yo tenía una compañera y en una fiesta yo había tenido un encuentro casual, digamos. Entonces fui cuestionado porque esas cosas no podían ser en un dirigente, digamos, en un revolucionario, porque en la vida de la unidad no sólo se abordaba el tema político general, sino que la cosa de los valores [es] muy importante. Entonces, se hace esta discusión sobre cuál es el comportamiento del revolucionario, cómo hacerlo, etc. Era una cuestión súper importante en la vida militante, te fijas. La cosa valórica era en nosotros una cuestión, súper pero súper importante.

De este modo, el MIR era el espacio de la revolución pero también el de los afectos, la amistad, el amor y las pasiones. La cantidad de tiempo que los miristas dedicaban a las actividades partidarias hacía prácticamente imposible construir relaciones de amistad o de pareja con personas ajenas a ese mundo. Por lo mismo, las rupturas, los reencuentros y la formación de nuevos vínculos ocurrían, en la mayoría de los casos, al interior de la organización. Esto fortalecía las fronteras que existían entre el mundo partidario y el mundo exterior, mientras que los contactos con el afuera eran cada vez más esporádicos y débiles. De acuerdo a la ex militante Lucrecia Brito, la formación de parejas entre compañeros era frecuente, mientras que las posibilidades de establecer relaciones afectivas con militantes de otras organizaciones enfrentaban algunos obstáculos:

bueno, a los comunistas le prohibían a sus militantes pololear con gente del MIR, y en el MIR no habían ese tipo de prohibiciones, nadie se metía en tu vida privada, aunque claro, no debe haber faltado el desviado que haya querido meterse con alguien de afuera, pero no era la conducta general.

En relación con este punto, si bien no existía ninguna orden partidaria que prohibiera $\mathrm{O}$ sancionara la formación de parejas con personas ajenas a la organización, esa posibilidad no sólo era improbable sino que constituía una situación "anómala y desviada", es decir, poco ajustada a lo considerado normal y correcto. Esta realidad, asumida y naturalizada por gran parte de la militancia aún sin existir una orden de por medio, no impidió que algunos militantes se vincularan afectivamente con personas que pertenecían al mundo del afuera. En estos casos, la articulación entre el compromiso de pareja y el compromiso partidario no estaba libre de tensiones y se organizaba de acuerdo a las prioridades del militante. Así lo recuerda el ex militante Enérico García:

\begin{abstract}
Yo tenía una polola que no era mirista, ella estaba sub-dedicada a mí, a mis tareas. O sea, yo no le iba a dedicar más tiempo a ella que a mi militancia. Ningún compromiso que yo tuviera con ella iba a ser más importante que el que yo tuviera con la organización. Yo me casé en el año 71 con ella, pero si ella no entendía, se acababa la relación, eso... si no entendía mi relación con la política, con esa forma de hacer política.
\end{abstract}

La masculinidad revolucionaria se expresaba y construía performáticamente (Butler 2002) en la escenificación cotidiana de la valentía, el arrojo y la audacia. El modelo se acerca al arquetipo del guerrero (siempre heterosexual) que seducía con su temeridad y capacidad de sacrificio a las mujeres, incluso a aquellas que eran ajenas al mundo de la militancia y que aceptaban y se adaptaban a sus exigencias y prioridades.

Es así como los rasgos asociados al modelo del "Hombre Nuevo" guevarista fortalecía la masculinidad de los militantes varones y los volvía más atractivos, incluso a aquellos débiles o disminuidos físicamente, ensanchando sus posibilidades de seducción. Para las mujeres, 
en cambio, el estilo de vida que exigía la construcción del socialismo y el cumplimiento de las exigencias que imponía el proyecto revolucionario las volvía menos femeninas en términos tradicionales, y las transformaba -en los hechos y sin, necesariamente, habérselo propuesto- en transgresoras del sistema sexogénero. Respecto a este punto, Lautaro Videla señala:

los hombres éramos suficientemente atractivos como para ser capaces de engrupir a una mina [sic] que nos veía de vez en cuando y a la que no podíamos ofrecer compromiso certero, pero éramos atractivos, del punto de vista no te digo a lo mejor físico, sino de lo que éramos, de lo que valíamos, de lo que pesábamos, de la huevá [sic] que estábamos. Es muy común que muchos miristas tuvieron de pareja a mujeres que eran más pasivas y que se adaptaron a nuestra condición errática, sin horario. En el caso de las mujeres, que eran menos, normalmente encontraban a su pareja entre los miristas y si no la encontraban lo pasaban mal, porque normalmente nadie se las calaba [sic] porque tenían que estar ahí en el ritmo que teníamos y que ningún hombre normal se las iba a calar [sic]. Pensaban que les estaban poniendo el gorro [sic].

Esa transgresión, muchas veces no buscada, tenía como consecuencia costos y tensiones específicas que imprimían a la militancia femenina un tono diferente a la masculina (Vidaurrázaga 2006). De hecho, la asociación entre la actividad política intensa y una sexualidad activa y poco ajustada a la moral conservadora es inmediata: "pensaban que les estaban poniendo el gorro". Como señala el testimoniante, pocos hombres estaban dispuestos a aceptar eso, salvo quienes pertenecían a la misma organización.

Hay que precisar que estos deslizamientos y fisuras dejaron intacta la centralidad del imperativo heterosexual, de modo que las organizaciones revolucionarias -al igual que los partidos tradicionales de izquierda, centro y derecha- reprodujeron en su interior las concepciones heterosexistas y homofóbicas de la sociedad que esperaban destruir. Un caso dramático es el de Mario Melo, militante que fue miembro de las FFAA y que durante el periodo de Frei Montalva fue expulsado del ejército por sus vínculos con el MIR. Una vez ocurrido el triunfo de Allende, se incorporó al GAP (guardia personal del presidente), y luego fue parte del aparato militar de la organización. Como tal, fue enviado a Cuba a formar cuadros en esa materia. Estando en la isla, circuló la información de que Melo era homosexual. Max Marambio, ex miembro del GAP, señala en una declaración judicial del año $2003^{13}$ :

[pensamos que] podía reportar un peligro para la organización del MIR teniendo en cuenta que él manejaba información sobre materias sensibles, como casa de seguridad y armamento. Ante eso el MIR optó por congelar la militancia de Melo y ordenarle que se quedara un año en Cuba (...). En todo caso, Mario Melo fue expulsado del MIR y obligado a permanecer en Cuba en tratamiento sicológico para superar su inclinación sexual. El día 11 de septiembre de 1973, Mario Melo encontrándose ya expulsado del MIR, se presentó en La Moneda subiéndose al techo del edificio y desde ahí disparó a los aviones que sobrevolaban el techo presidencial. El hecho de que Mario hubiese ido a la Moneda no teniendo ninguna obligación de hacerlo refleja su lealtad.

La declaración de Max Marambio fue publicada en la prensa en octubre del año 2009. De acuerdo al reportaje ("Max Marambio revela el secreto mejor guardado del MIR", de Jorge Molina Sanhueza): "[estando] en Cuba, Melo fue expulsado del MIR y se le sometió a un tratamiento siquiátrico para cambiar su inclinación sexual, donde los médicos concluyeron que, sencillamente, era así y que nada lo iba a cambiar. Mario les contó a los médicos historias terribles, como que por años se había tratado en Chile para evitar ser así" (...). "Sin embargo, el hecho no cayó nada bien en un sector del MIR. Algunos miembros que estaban en Cuba se reunieron con Marambio sugiriéndole que Melo debía ser eliminado. [Marambio] evitó que ello sucediera, no sin un fuerte altercado de por medio". El Mostrador. Santiago, 5 de Octubre de 2009. 
La comprensión de la homosexualidad como desviación peligrosa fue parte de un ideario en el que los valores revolucionarios (fuerza, audacia, coraje, decisión) eran, al mismo tiempo, los ideales masculinos tradicionales. De acuerdo a este universo de representaciones, ser un buen revolucionario era lo mismo que ser un buen hombre. Asimismo, la debilidad, la flaqueza, el temor y la cobardía eran asociadas a la "falta de huevos" y a conductas pequeño burguesas (o abiertamente contrarrevolucionarias) que era preciso erradicar. De esta forma, la hombría y la revolución estaban entrelazadas simbólicamente, y se definían por oposición a lo femenino (y homosexual).

En su análisis sobre la masculinidad revolucionaria cubana, Silje Lundgren (2010) señala que en el escenario post-revolucionario se implementaron políticas basadas en la noción estalinista sobre la homosexualidad. Comprendida como expresión de la decadencia burguesa y como vicio capitalista, se resolvió poner en marcha campos de trabajo (Unidades Militares de Ayuda a la Producción) destinados a reeducar y a curar a individuos cuyas conductas se distanciaban del modelo de "Hombre Nuevo" que la sociedad cubana esperaba construir. De este modo, homosexuales, religiosos, contrarrevolucionarios, y otros individuos con conductas contrarias a la ética y moral revolucionaria, debían rehabilitarse a través del trabajo físico ${ }^{14}$.

En cuanto al tema de los hijos e hijas, en el período comprendido por este trabajo, el MIR no definió una política específica para sus militantes, y de acuerdo a los testimonios

14 De acuerdo a Lundgren (2010), estos sitios funcionaron sólo entre 1965 y 1967 . Pese a su breve historia, se transformaron en el símbolo de la homofobia revolucionaria. analizados, es posible apreciar que muchas mujeres decidieron postergar la maternidad para que su trabajo partidario no se viese afectado. Ahora bien, esto no significa que los militantes miristas no tuvieran hijos; de hecho, un número importante de ellos sí fueron padres y madres, como sucedió con la mayoría de sus dirigentes. En esos casos, o las mujeres abandonaban total o parcialmente la militancia, o dejaban a sus hijos al cuidado de sus abuelos para poder mantener el mismo nivel de compromiso militante (Vidaurrázaga 2006).

Es interesante constatar que la familia de origen - desplazada o abandonada por la nueva familia mirista- fue la que asumió las responsabilidades que los militantes desatendieron o postergaron al estar absorbidos por las urgencias de la revolución. De esta manera, el cuidado y la crianza de los(as) niños(as), e incluso la mantención material de los propios miristas, fue asumida por padres y madres que no necesariamente compartían los ideales políticos de sus hijos e hijas militantes. Luis Ulloa, ex militante del MIR, lo recuerda así:

\footnotetext{
Y bueno los hijos quedaron... había muchas mamás cuidando los hijos, porque tú tenías un hijo y si andabai [sic] prófugo tu mamá terminaba criando ese hijo, hay muchas mamás de militantes del MIR que terminaron criando a sus hijos, a mí me pasó, a mi hijo mayor lo terminaron criando mis padres, ellos se hacían cargo de ese costo, yo ahora valoro esas cosas, antes consideraba que era casi su obligación.
}

Independiente de la forma en que el tema de la paternidad y la maternidad se enfrentara, lo cierto es que el asunto pareció ser una preocupación que afectaba únicamente a las mujeres, a las que en no pocas ocasiones se les exigió que eligieran entre una y otra función. En este sentido, la promesa emancipadora de la revolución socialista era vivida y sentida de 
un modo diferenciado por hombres y mujeres, y ofrecía a estas últimas tensiones y obstáculos que debieron enfrentar solas. Tal como señala la ex dirigente y periodista Gladys Díaz:

\begin{abstract}
Yo tuve un hijo cuando muy pocos miristas tenían hijos, entonces era re poco entendido el tema de la maternidad. Yo recuerdo una vez haber sido sancionada porque no fui a una reunión porque tenía a mi hijo con neumonía, porque no entendían, no entendían (...). Yo recuerdo que un dirigente de la Comisión Política me dijo que tenía que elegir entre ser miembro del Comité Central o madre porque no podía ser las dos cosas, y yo le dije: "y ¿por qué tú sí?" Y la respuesta fue: "Ah porque yo tengo una mujer que se preocupa de mis hijos". Y yo, como yo no tenía un hombre que se preocupara de mi hijo... Al final, tú siempre cargaste la militancia con una culpa respecto de tu maternidad.
\end{abstract}

\section{A modo de conclusión}

Siguiendo los planteos de Raymond Williams (2009), la idea de revolución fue vivida y sentida de un modo particular por los militantes del MIR. En este marco, la obediencia de los militantes y su acatamiento a las órdenes superiores no se explican únicamente por la dimensión punitiva de la experiencia política. Hubo también otros elementos que explican por qué las personas decidieron cumplir los mandatos de sus dirigentes, aún en escenarios en que la derrota se hacía evidente. En el escenario posterior al Golpe de Estado, el temor a ser sancionado fue un elemento más entre varios otros, y es probable que ni siquiera haya sido el más decisivo a la hora de explicar las razones que llevaron a muchos militantes a mantenerse dentro de sus organizaciones disciplinadamente, aun cuando podían percibir que la realidad desmentía los análisis que los dirigentes elaboraban, y que las políticas implementadas estaban condenadas al fracaso.
Muchos militantes se refieren a la sensación de que todos los errores y deficiencias estaban justificados, ya que el fin último del proyecto era justo. No importaban las imperfecciones que se cometieran en el camino, pues la meta final sería beneficiosa para toda la humanidad. Probablemente, en especial después del golpe de septiembre de 1973, ya no se confiaba ciegamente en la inmediatez del triunfo, pero se asumía que serían otros los que podrían beneficiarse del sacrificio personal y colectivo de los militantes.

Otra razón para continuar militando sin cuestionar mayormente las órdenes de la Dirección, era la sensación de deuda con los amigos y los compañeros fallecidos y/o desaparecidos. Esas muertes operaban como un mandato de continuidad, y la posibilidad de renunciar era percibida como una suerte de traición a esas vidas sacrificadas. Si los otros habían dejado la vida en la lucha, no había derecho a no hacer lo mismo. Abandonar la militancia era abandonarlos a ellos, traicionado su memoria.

Asimismo, estaba presente la idea de haber emprendido un camino sin retorno, un camino en el que, como había afirmado Ernesto Guevara, se triunfaba o se moría, si es que era verdadero. La proximidad de la muerte propia del escenario represivo posterior al golpe cívico-militar, no hacía sino confirmar que las decisiones tomadas eran definitivas, y que la opción por la revolución no admitía dudas ni temores. La lucha era real y era preciso llegar hasta las últimas consecuencias.

Del mismo modo, y como ya ha sido señalado, el MIR se transformó en un espacio afectivo vital y primario para sus miembros. El mundo y la vida ocurrían al interior de esa comunidad, 
y la política y los afectos eran parte de un todo indisoluble. Por lo tanto, ser expulsados de la organización era una especie de destierro político, social y emocional que había que evitar a toda costa. Al mismo tiempo, ser parte de la organización era sinónimo de ser parte de la historia, era la posibilidad de ser protagonistas del mayor y más noble de los proyectos históricos (Bastías 1995).

Este aspecto explica, al menos en parte, la existencia de una cultura mirista (Goicovic 2012), de un ethos militante que ha persistido en el tiempo más allá de la existencia orgánica y formal de la organización, cuestión que debería ser abordada por futuras investigaciones. Por último, la intensidad de la vida partidaria se nutría tanto de la vida como de la muerte, pues -desde la perspectiva militante- al mismo tiempo que se creaba una realidad nueva y se era protagonista del más hermoso proyecto histórico posible -la revolución-, esa misma plenitud de vida ponía a los militantes al borde del abismo y los dejaba expuestos a la tortura y la muerte. La pasión revolucionaria fue vivida en los dos sentidos del término: como fervor, exaltación e ímpetu, y también como padecimiento, tormento y muerte.

\section{Bibliografía}

Almond, G. A. y Powell, G. B. 1966. Comparative politics: A developmental approach. Boston: Little Brown.

Bastías, J. 1995. "A propósito del MIR chileno. Un intento de psicología partidaria. Representaciones sociales y subsistemas ideológicos como factores de inhibición en la crítica de los militantes". Psicología de la acción política. D’Adamo, O. et al. (Coords.). Buenos Aires: Paidós. 120-146.

Badiou, A. 2005. El siglo. Buenos Aires: Manantial.

Butler, J. 2002. Cuerpos que importan. Buenos Aires: Paidós.

Calderón, L. 2009. La política del Movimiento de Izquierda Revolucionaria (MIR) durante los dos primeros años de la dictadura militar (1973-1975). Entre la lucha por convertirse en actor político y la lucha por sobrevivir. Tesis para optar al grado de Licenciado en Historia. Santiago: Universidad de Santiago de Chile.

Devés, E. 2003. El pensamiento latinoamericano en el siglo XX. Desde la CEPAL al neoliberalismo (1950-1990). Santiago: Biblos.

Fernández, F. 1999. Escritos revolucionarios. Madrid: Catarata.

Goicovic, I. 2012. Movimiento de Izquierda Revolucionaria. Concepción: Escaparate.

Lechner, N. 1987. Cultura política y democratización. Santiago: CLACSO-FLACSO-ICI.

1986. La conflictiva y nunca acabada construcción del orden deseado. Madrid: Siglo XXI.

Leiva, S. 2010. Revolución socialista y poder popular.
Los casos del MIR y el PRT-ERP 1970-1976. Santiago: Escaparate.

Lundgren, S. 2010. "Igualdad y diferencia: Dinámica entre ideales de género de la vida cotidiana y el discurso estatal cubano". Cuadernos Ruth de Pensamiento Crítico 5: 81-97.

Mariátegui, J. C. 1988. El alma matinal y otras estaciones del hombre de hoy. Lima: Amauta. 1934. Defensa del marxismo. Santiago: Cultura.

MIR. 1974. "¡A fortalecer nuestro partido! Los golpes recientes, algunas lecciones y la reorganización de las direcciones". Miguel Enríquez. Con vista a la esperanza. Radrigán, C. y Ortega, M. (Eds.). Santiago: Escaparate. 336-337.

Naranjo, P. et al. 2004. Miguel Enríquez y el proyecto revolucionario en Chile. Discursos y documentos del Movimiento de Izquierda Revolucionaria MIR. Santiago: LOM.

Oberti, A. 2011. Género, política y violencia. Vida cotidiana y militancia en las décadas del sesenta y setenta. Tesis para optar por el grado de Doctora en Ciencias Sociales. Buenos Aires: Universidad de Buenos Aires.

Palieraki, E. 2014. ¡La revolución ya viene! EI MIR chileno en los años sesenta. Santiago: LOM.

Pinto, J. 2006. "¿Y la historia les dio la razón? EI MIR en dictadura, 1973-1981". Su revolución contra nuestra revolución. Izquierdas y derechas en el Chile de Pinochet (1973-1981). Valdivia, V. et al. (Autores). Santiago: LOM. 
153-205.

. 2005. "Hacer la revolución en Chile". Cuando hicimos historia. La experiencia de la Unidad Popular. Pinto, J. (Ed.). Santiago: LOM. 9-34.

Rivas, P. 2007. Chile. Un largo septiembre. Santiago: LOM.

Ruiz, M. O. 2014. Historias y memorias de traición. Subjetividad revolucionaria, mandatos militantes y traición en el Partido Revolucionario de los Trabajadores-Ejército Revolucionario del Pueblo (PRT-ERP), Montoneros y el Movimiento de Izquierda Revolucionaria (MIR) en las décadas del sesenta y setenta. Tesis para optar al grado de Doctora en Estudios Latinoamericanos. Santiago: Universidad de Chile.

Sandoval, C. 2004. Movimiento de Izquierda
Revolucionaria, 1970-1973. Vivencias, documentos y coyunturas. Concepción: Escaparate. 1990. M.I.R.: Una historia. Santiago: Sociedad Editorial Trabajadores.

Sorel, G. 2005. Reflexiones sobre la violencia. Madrid: Alianza Editorial.

Subercaseaux, B. 2004. Historia de las ideas y de la cultura en Chile. Vol. III. Santiago: Editorial Universitaria.

Vidal, H. 1999. Presencia del MIR. 14 claves existenciales. Santiago: Mosquito Editores.

Vidaurrázaga, T. 2006. Mujeres en rojo y negro. Reconstrucción de memoria de tres mujeres miristas 1971-1990. Santiago: Escaparate.

Williams, R. 2009. Marxismo y literatura. Buenos Aires: Editorial Las Cuarenta. 